Molecules 2008, 13, 391-404

\title{
molecules
}

ISSN 1420-3049

(C) 2008 by MDPI

www.mdpi.org/molecules

Review

\section{Novel Prodrugs for Targeting Diagnostic and Therapeutic Radionuclides to Solid Tumors}

\author{
Amin I. Kassis*, Houari Korideck, Ketai Wang, Pavel Pospisil and S. James Adelstein \\ Department of Radiology, Harvard Medical School, Armenise Building, Room D2-137, 200 \\ Longwood Avenue, Boston, Massachusetts 02115, USA \\ *Author to whom correspondence should be addressed. Telephone: (617) 432-7777; Fax: (617) 432- \\ 2419; E-mail: amin_kassis@hms.harvard.edu
}

Received: 6 February 2008 / Revised version received: 15 February 2008 / Accepted: 15 February 2008 / Published: 18 February 2008

\begin{abstract}
Most cancer therapeutics (chemo, radiation, antibody-based, anti-angiogenic) are at best partially and/or temporarily effective. In general, the causes for failure can be summarized as: (i) poor diffusion and/or nonuniform distribution of drug/prodrug molecules in solid tumors; (ii) high drug concentration and retention in normal tissues (leading to side effects); (iii) requirement for plasma-membrane permeability and/or internalization of drug/prodrug molecules; (iv) low uptake of drug by tumor; (v) lack of retention of drug within tumor (most have gradient-driven reversible binding); and (vi) multidrug resistance. We are developing an innovative technology that aims to surmount these problems by actively concentrating and permanently entrapping radioimaging and radiotherapeutic prodrugs specifically within solid tumors. The approach will enable noninvasive sensing (imaging) and effective therapy of solid tumors, allowing tumor detection, diagnosis, and treatment to be closely coupled (personalized medicine).
\end{abstract}

Keywords: Prodrug, solid tumors, radioiodine, radioimaging, radiotherapy

\section{Introduction}

We are developing an innovative technology that aims to actively concentrate and permanently entrap radioimaging and radiotherapeutic prodrugs (RIPD and RTPD, respectively) specifically within 
solid tumors. The approach, which we have named Enzyme-Mediated Cancer Imaging and Therapy (EMCIT), is a method for extracellular enzyme-dependent, tumor-specific, in vivo hydrolysis of watersoluble RIPD/RTPD to water-insoluble precipitating entities that are entrapped within solid tumors [18]. This paper will summarize our recent findings and discuss some of the advantages of targeting radioactive prodrugs to solid tumors.

Over the past 30 years, the number of cancer deaths has doubled and now exceeds 500,000 per year. Although major advances have taken place in radiation therapy, surgery, and the systemic treatment of cancer, one in three people living in the USA will develop cancer and one in five of these will die of the disease. It is evident that the development of technologies that enable noninvasive detection and therapy of solid tumors, especially at the earliest time points, is highly desirable and will be beneficial. Such technologies will: (i) move meaningful intervention to a much earlier point in the path of tumor progression, thereby forestalling the development of metastatic disease; (ii) minimize patient inconvenience and incapacitation; and (iii) allow tumor detection, diagnosis, and treatment to be closely coupled.

One strategy for providing substantial increases in the clinical efficacy of agents that preferentially kill tumor cells is the use of a relatively nontoxic molecule (prodrug) that can be activated selectively to a toxic analog within solid tumors. Prodrugs are generally defined as chemicals that are transformed after administration, either by metabolism or spontaneous chemical breakdown, to pharmacologically active species (drugs). Chemotherapeutic prodrugs have at least four major intrinsic weakness: (i) the pharmaceutical must distribute uniformly within the entire solid tumor mass; (ii) being nonradioactive, therapeutic concentrations of these molecules must be delivered to each tumor cell; (iii) upon conversion to drugs, the molecules must have the capacity to permeate into the targeted cells; and (iv) the drug molecules are likely to diffuse out of the targeted tumor and, therefore, to kill nontargeted normal cells. In the EMCIT approach, a water-soluble RIPD/RTPD is hydrolyzed to a highly waterinsoluble form (i.e., a precipitate) by enzymes that are specifically overexpressed within the extracellular spaces of solid tumors and minimally expressed within normal tissues (Figure 1). We anticipate that the administration of RIPDs and RTPDs will lead to the specific in vivo entrapment of radioactivity within the extracellular matrix/space of solid tumors and, therefore, will be useful in the noninvasive radiodetection $\left({ }^{123} \mathrm{I} /{ }^{124} \mathrm{I} /{ }^{131} \mathrm{I}\right)$ and radiotherapy $\left({ }^{131} \mathrm{I}\right)$ of primary tumors and their metastases. We expect the EMCIT technology will overcome the major limitations of chemotherapeutic prodrugs mentioned above, since RTPDs (i) do not need to be uniformly distributed within solid tumors in order to be therapeutically efficacious (due to cross-fire irradiation consequent to the long range of the $\beta$-particles emitted by the decaying isotope) [9]; (ii) are permanently retained within the extracellular space of solid tumors following their hydrolysis and precipitation (no efflux from within the tumor mass and, therefore, minimal side effects); (iii) do not need to permeate their targeted tumor cells to be therapeutic; and (iv) are negatively charged and not internalized by cells (protected from intracellular hydrolases and from the complications associated with multidrug resistance).

To fulfill the promise of EMCIT technology, we took advantage of: (i) the wealth of information that is being generated as a consequence of major advances in the understanding of the genetic basis of cancer, including changes in the genome and the expressed products of the genome; (ii) the ability to mine effectively and methodically various databases for specific tumor-cell signatures, such as 
hydrolytic enzymes specifically overexpressed extracellularly by human tumor cells; (iii) recent advances in computer-assisted molecular modeling that can help (a) identify and characterize the active site(s) of biologically active molecules, such as hydrolytic enzymes, (b) define pharmacophores whose atoms/centers interact with and bind to the bioactive site(s) of the identified enzymes, and (c) identify and design chemical structures that have the physical, chemical, and biologic characteristics necessary for the development of RIPDs and RTPDs. This review summarizes our in silico datamining work and some of the radioiodinated prodrugs synthesized and tested in vitro and in vivo.

Figure 1. Schematic diagram of EMCIT technology.

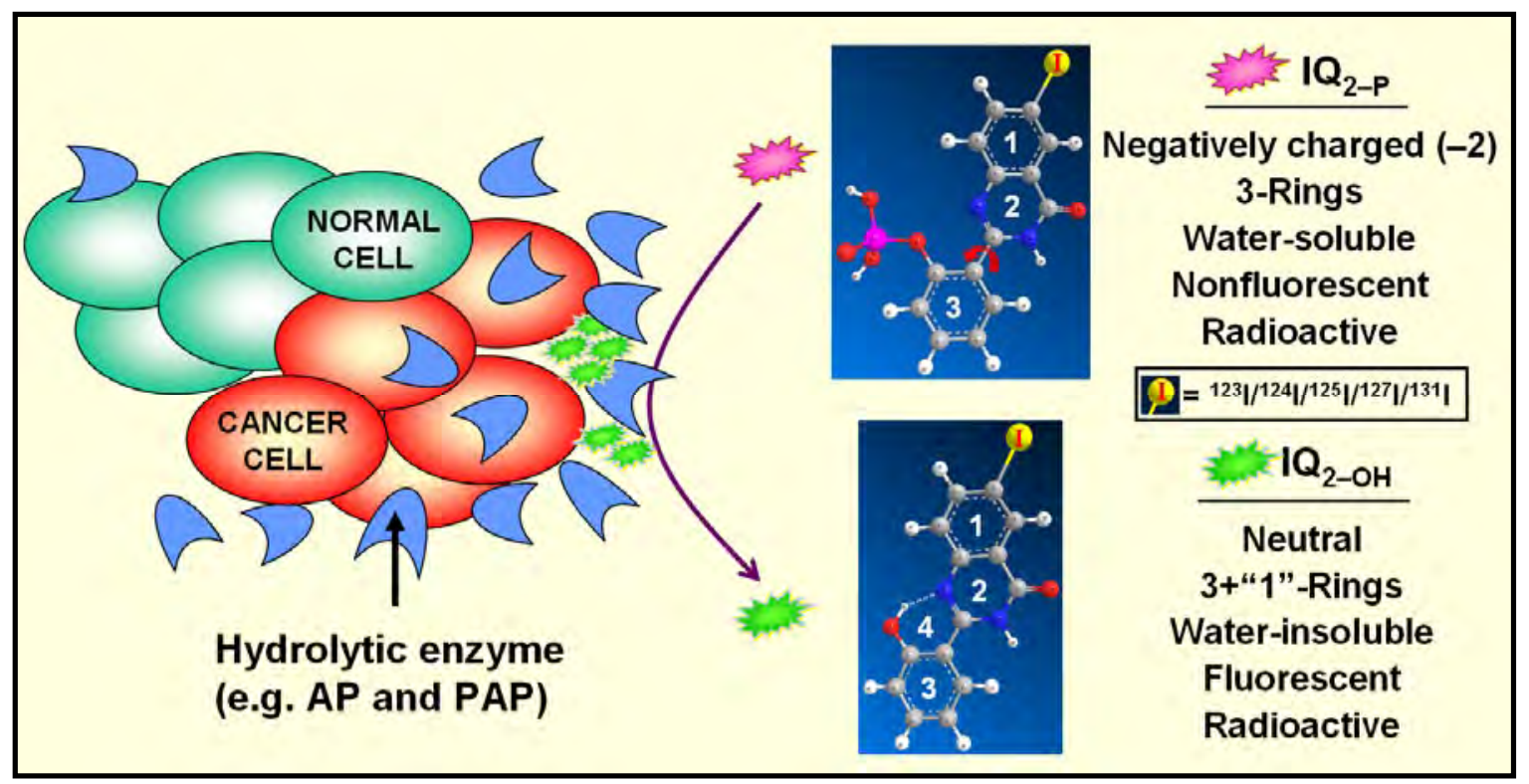

\section{Data Mining}

Recent advances in genomics and associated high throughput technologies have resulted in the exponential growth of biologic databases. Deriving biologic insights from these unprecedented quantities of data is challenging. In recent years, data mining and tools for retrieval of information have made considerable progress. However, several problems persist: (i) inefficient search engines associated with databases; (ii) incorrect or incomplete annotations of entities; (iii) constant need for annotation updates and for query-tool improvements; and (iv) complexity of the biologic phenomena and biologic systems. Moreover, various databases and their associated tools provide information at different levels of reliability and accuracy [10].

We recently formulated a systematic strategy for data mining that aims to address the abovementioned problems [4]. It is based on searching the major gene/protein sequence/structure/motif repositories and available knowledge bases with user-defined criteria that lead to the detection of cancer-specific enzymes with hydrolytic activities, overexpressed in the extracellular space of solid tumor cells. In the first phase of our studies, the intent was the development of facile and reliable datamining approaches that enable the identification of extracellular hydrolases suited for the EMCIT technology. Specifically, our sequence of procedures explored PubMed abstracts [11], gene/protein 
databases - UniProt [12] and NCBI Entrez Gene [13], and state-of-the-art pathway knowledge bases IT.Omics LSGraph ${ }^{\circledR}$ [14] and Ingenuity ${ }^{\circledR}$ Systems, Ingenuity Pathway Analysis (IPA) [15]. Our efforts led to the development of a unique data-mining approach [4] that enabled the identification of hydrolases overexpressed extracellularly by human tumors (e.g., breast, colon, lung, ovary, pancreas, and prostate). Among the various human cancer-specific hydrolases identified ( 30 per cancer type, e.g., phosphatases, peptidases, sulfatases, and metalloproteinases), the plasma membrane tethered alkaline phosphatase (AP) and the secreted prostatic acid phosphatase (PAP) were selected for further studies since: (i) both are known to be minimally expressed by most normal cells and to be overexpressed by many tumor cells, and (ii) in tumor-bearing mice and in cancer patients, APexpressing tumors have been targeted and imaged successfully with radiolabeled anti-AP antibodies [16-19].

\section{In Silico Molecular Modeling Studies}

The second phase of our work was aimed at the in silico characterization of the binding pocket of the hydrolases identified through data mining, definition of possible pharmacophores and examination of their interactive mode with both enzymes, and systematic performance of three-dimensional, quantitative structure-activity relationship analysis. We describe herein our findings with AP, an enzyme that: (i) is overexpressed on the cell surface; and (ii) is involved in cancer. This enzyme was also chosen since the Protein Data Bank search afforded a total of 40 matches of available structure models of AP or AP-substrate/AP-inhibitor complexes, including a high resolution structure of the human placental alkaline phosphatase isoform (PLAP) determined at $1.8 \AA$ resolution (PDB code 1EW2) [20].

Our in silico studies indicated that the active site of PLAP involves various amino acids, metals, and a phosphate. The structure also suggests that there is a hydrophillic pocket in the active site and that the phosphate-PLAP interaction involves Glu429 and Arg166. The participation of these two amino acids allows precise description of this pocket, which probably stabilizes the hydrophilic moiety of the substrate. Located at the entrance of the cleft that leads to the active site, Glu429 borders a pocket that extends from the catalytic Ser92 to the tightly bound phosphoryloxy moiety within the iodoquinazolinone substrate (Figure 1). In addition, several water molecules are located within the active site, and they form an extensive hydrogen-bonding network. Moreover, the three metals, two $\mathrm{Zn}^{2+}$ (referred as $\mathrm{Zn} 1$ and $\mathrm{Zn} 2$ ) and one $\mathrm{Mg}^{2+}$ are close in space: $\mathrm{d}(\mathrm{Zn} 1-\mathrm{Zn} 2)=4.02 \AA, \mathrm{d}(\mathrm{Zn} 2-\mathrm{Mg})=$ $4.76 \AA$, and $d(\mathrm{Zn} 1-\mathrm{Mg})=7.00 \AA$. The amino acid residues (especially catalytic Ser92) and the metal triplet (especially Zn1) are the core of the active site, which has been shown to participate in PLAPmediated hydrolysis of phosphoryloxy groups [21].

2-(2'-Phosphoryloxyphenyl)-6-iodo-4-(3H)-quinazolinone $\left(\mathrm{IQ}_{2-\mathrm{P}}\right)$ is a relatively flexible molecule in which two rings, the quinazolinone moiety and the benzene ring, are joined via a single rotatable $\mathrm{C}$ $\mathrm{C}$ bond (Figure 1). The phosphorus group is also quite free since it is connected with the benzene ring through a single $\mathrm{P}-\mathrm{O}-\mathrm{C}$ bond. Along the PLAP active site, the quinazolinone moiety packs in the upper cleft of the binding pocket, and the iodine atom poses against the pocket (Figure 2). In order to be positioned in the middle of the binding pocket, the benzene ring adopts non-coplanar conformation with the quinazolinone ring. The phosphorus group of $\mathrm{IQ}_{2-\mathrm{P}}$ twists slightly to allow itself to drop 
completely into the bottom of the binding pocket and forms a number of H-bonds with amino acid residues in the active site. Most important, the phosphorus group of $\mathrm{IQ}_{2-\mathrm{P}}$ has hydrogen bonding with the catalytic amino acid Ser92, indicating that the molecule can be easily dephosphorylated. After $\mathrm{IQ}_{2-}$ p was docked into PLAP, the free binding energy $(\Delta G)$ and inhibition constant $\left(K_{\mathrm{i}}\right)$ of its lowest energy poses with PLAP were calculated, both predictions derived from the AutoDock algorithm. Among the derivatives examined, the binding affinity of this analog was most favorable (Table 1), i.e., very likely to lead to AP-mediated dephosphorylation.

Figure 2. In silico docking positions of $\mathrm{IQ}_{2-\mathrm{P}}$ in active site of $\mathrm{AP}$.

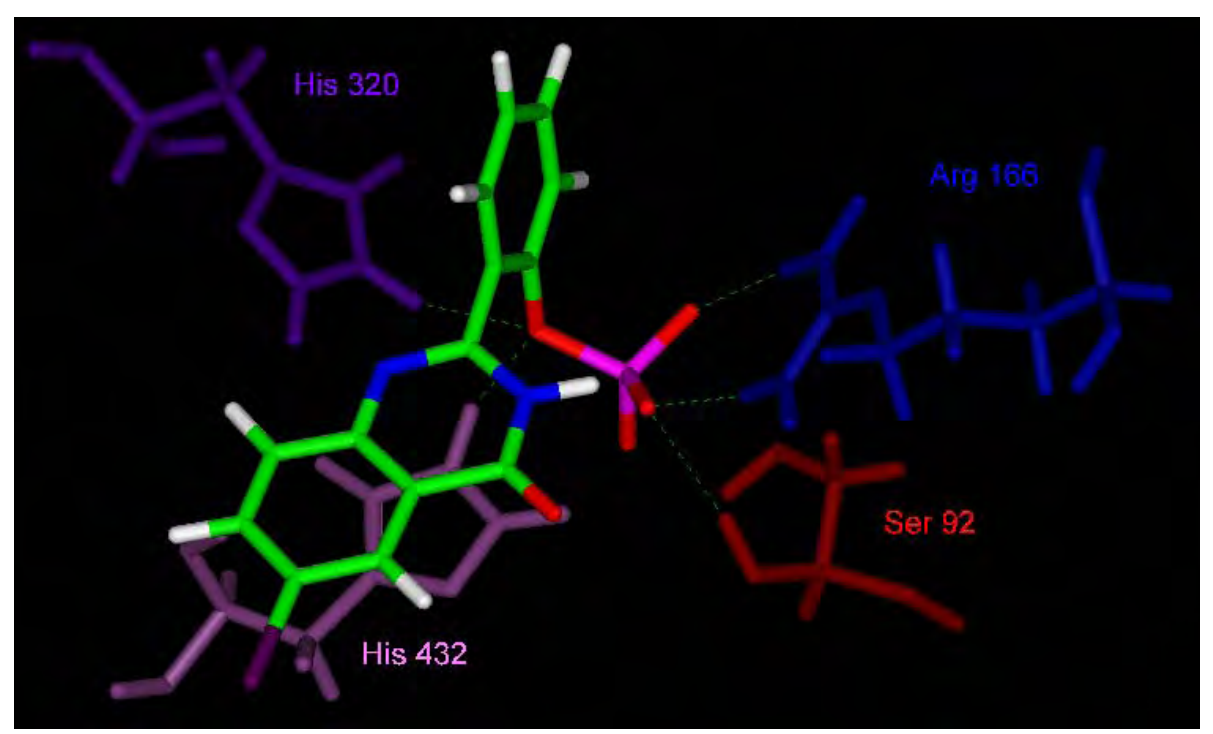

\begin{tabular}{|c|c|c|c|c|}
\hline Structure & $\begin{array}{c}\text { Phosphate } \\
\text { Position }\end{array}$ & $\begin{array}{l}\text { lodine } \\
\text { Position }\end{array}$ & $\begin{array}{l}\text { Binding } \\
\text { Free } \\
\text { Energy } \\
\text { (kcal/mol) }\end{array}$ & $\mathbf{K}_{\mathbf{i}}$ \\
\hline Ammonium-2-(4'-phosphoryloxyphenyl)-4-(3H)-quinazolinone & 4- & - & -10.24 & 3.10E-08 \\
\hline Ammonium-2-(2',4'-diphosphoryloxyphenyl)-8-iodo-4-(3H)-quinazolinone & 2,4- & 8- & -12.24 & 1.06E-09 \\
\hline Ammonium-2-(2',6'-diphosphoryloxyphenyl)-6-iodo-4-(3H)-quinazolinone & 2,6- & 6- & -12.1 & 1.35E-09 \\
\hline Ammonium-2-(4'-phosphoryloxyphenyl)-6-iodo-4-(3H)-quinazolinone & 4- & 6- & -11.51 & 3.64E-09 \\
\hline Ammonium-2-(2',4'-diphosphoryloxyphenyl)-7-iodo-4-(3H)-quinazolinone & 2,4- & 7- & -11.55 & $3.40 E-09$ \\
\hline Ammonium-2-(2'-phosphoryloxyphenyl)-6-iodo-4-(3H)-quinazolinone & 2- & 6- & -12.86 & 3.77E-10 \\
\hline
\end{tabular}

We also docked $\mathrm{IQ}_{2-\mathrm{P}}$ into human PAP. This hydrolase possesses protein tyrosine phosphatase activity and is known to be secreted as a glycosylated homodimer in the seminal fluid of the prostate gland [22]. Like most phosphomonoesterases, it hydrolyzes a wide spectrum of substrates, including alkyl, aryl, and other phosphate derivatives [22,23]. In this case, the phosphorus atom is at a favorable distance for nucleophile attack by His12, leading to the dephosphorylation of $\mathrm{IQ}_{2-\mathrm{P}}$, in agreement with the theoretical axial attack of $\mathrm{P}$ by this nucleophile $[24,25]$. The iodine atom of the quinazolinone points outward from the active site and does not hinder the binding to PAP. Moreover, the position of $\mathrm{IQ}_{2-\mathrm{P}}$ results in 11 hydrogen bonds and highly favorable binding free energy $(-13.39 \mathrm{kcal} / \mathrm{mol})$ thereby indicating that this molecule should also be an excellent substrate for PAP. 
Synthesis, Radioiodination, and Characterization of $Q_{2-P}$ Derivatives [5-7]

We have utilized traditional approaches for the synthesis and characterization of several 2-(2'hydroxyphenyl)-4-(3H)-quinazolinone $\left(\mathrm{Q}_{2-\mathrm{OH}}\right)$ and ammonium 2-(2'-phosphoryloxyphenyl)-4-(3H)quinazolinone $\left(\mathrm{Q}_{2-\mathrm{P}}\right)$ derivatives.

Water Solubility of Iodinated $Q_{2-P}$ and $Q_{2-\mathrm{OH}}$ Derivatives

Since the EMCIT technology depends on the conversion of a water-soluble, phosphorylated quinazolinone analog to a highly water-insoluble, dephosphorylated analog, the solubilities of these molecules in water have been determined. These experiments (Table 2 within Figure 3) show that the dephosphorylation of the $\mathrm{Q}_{2-\mathrm{P}}$ analogs, i.e., the formation of corresponding $\mathrm{Q}_{2-\mathrm{OH}}$ derivatives, leads to a $>10^{6}$-fold reduction in the water solubility of these compounds (from $\sim 2-8 \mathrm{mg} / \mathrm{mL}$ to $\sim 1-10 \mathrm{ng} / \mathrm{mL}$ ).

Figure 3. Structure and water solubility of iodinated quinazolinone derivatives.

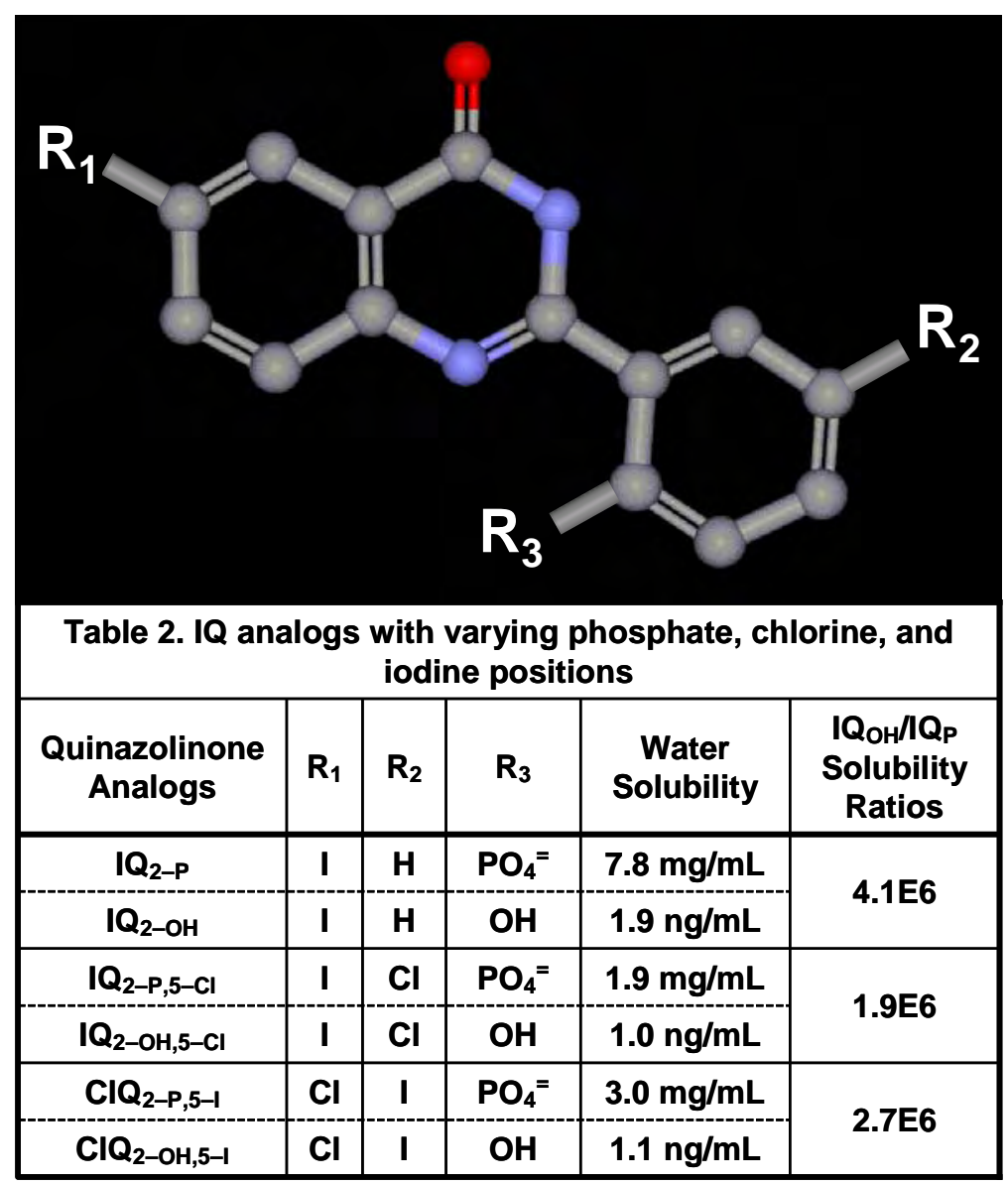

\section{AP- and PAP-Dependent Conversion of Iodoquinazolinone Derivatives}

When the nonfluorescent and water-soluble phosphoryloxyphenyl-iodoquinazolinone analogs $\left(\mathrm{IQ}_{\mathrm{P}}\right)$ are incubated with AP or PAP and the kinetics of hydrolysis are followed, a rapid increase in fluorescence intensity is seen, demonstrating the hydrolysis of $\mathrm{IQ}_{\mathrm{P}}$ and the formation of 
hydroxyphenyl-iodoquinazolinone analogs $\left(\mathrm{IQ}_{\mathrm{OH}}\right)$. Similarly, the incubation of ${ }^{125} \mathrm{IQ}_{\mathrm{P}}$ with either phosphatase ( $\mathrm{pH} 7.4$ ) leads to the quantitative (>98\%) hydrolysis of these analogs and the appearance of IQон.

Phosphatases, such as AP and PAP, are often elevated in the sera of patients with cancer and certain other diseases. However, the minimal AP and PAP concentrations needed to hydrolyze ${ }^{125} \mathrm{IQ}_{2-\mathrm{P}}$ are higher than those reported in the blood of patients with various cancers. Consequently, such radioiodinated quinazolinone derivatives are not expected to be hydrolyzed by phosphatases present in the circulation after their intravenous (i.v.) injection into cancer patients.

Until recently, it was assumed that the intracellular $\mathrm{pH}\left(\mathrm{pH}_{\mathrm{i}}\right)$ of tumor cells is acidic. However, it has become apparent that the $\mathrm{pH}_{\mathrm{i}}$ of tumors is in fact either neutral or slightly alkaline [26,27], whereas the extracellular $\mathrm{pH}\left(\mathrm{pH}_{\mathrm{e}}\right)$ is acidic [28]. On the other hand, the $\mathrm{pH}_{\mathrm{i}}$ and $\mathrm{pH}_{\mathrm{e}}$ of normal tissues are neutral. Consequently, extracellular proteins, such as secreted PAP and glycophosphotidylinositolanchored AP, as well as therapeutic molecules unable to permeate into cells, such as IQP analogs, are exposed to the acidic environment of solid tumor masses and the neutral milieu of normal tissues. As the optimum $\mathrm{pH}$ for $\mathrm{AP}$ is $>9$ and that for PAP for many substrates is $\sim 6$, it was essential to assess the effect of $\mathrm{pH}$ on the hydrolysis of $\mathrm{IQ}_{\mathrm{p}}$. Our studies, in which ${ }^{125} \mathrm{IQ}_{\mathrm{P}}$ was incubated in buffers (pH 3-12) containing AP and PAP, show that dephosphorylation for both hydrolases occurs most efficiently at a $\mathrm{pH}$ of $\sim 6$ (Figure 4). Consequently, iodoquinazolinone analogs are expected to be more readily hydrolyzed within the extracellular spaces of solid tumor compared with normal tissues consequent to the lower $\mathrm{pH}_{\mathrm{e}}$ of tumors as well as the overexpression of AP and PAP in various tumors.

\section{In Vitro and In Vivo Studies}

Hydrolysis of $\mathrm{IQ}_{2-P}$ by Mammalian Cells [3,5-7]

2-(2'-Phosphoryloxyphenyl)-6-iodo-4-(3H)-quinazolinone ( $\left.\mathrm{IQ}_{2-\mathrm{P}}\right)$ is a negatively charged molecule that is not internalized by mammalian cells. Since many tumors are known to overexpress phosphatases [29-37], we examined the ability of various viable human and mouse tumor cell lines grown in vitro or in vivo - to hydrolyze the nonfluorescent and water-soluble, iodinated $\mathrm{Q}_{2-\mathrm{P}}$ derivatives ( $\mathrm{IQ}_{2-\mathrm{P}}, \mathrm{IQ}_{2-\mathrm{P}, 5-\mathrm{Cl}}$, and $\left.\mathrm{ClQ}_{2-\mathrm{P}, 5-\mathrm{I}}\right)$ to the fluorescent and water-insoluble iodinated $\mathrm{Q}_{2-\mathrm{OH}}$ analogs. The data demonstrate that all such iodoquinazolinone derivatives are readily dephosphorylated by human tumor cells (Figure 5) and various mouse tissues and are not dephosphorylated by viable normal mammary and prostate cells [3,5-7]. However, both the size and intensity of the fluorescent crystals formed vary greatly $\left(\mathrm{IQ}_{2-\mathrm{OH}}>\mathrm{IQ}_{2-\mathrm{OH}, 5-\mathrm{Cl}}>\mathrm{ClQ}_{2-\mathrm{OH}, 5-\mathrm{I}}\right)$. It is difficult to predict the influence of such interplay of variables on the in vivo mediated, tumor-induced hydrolysis of iodinated $\mathrm{Q}_{2-\mathrm{P}}$ derivatives, especially since similar $\Delta G$ were obtained in silico for all these derivatives. Finally, we found that most of these extracellular crystals (>98\%) are washed away when the cells are rinsed, but that a few crystals are always seen irreversibly bound to the tumor cells (Figure 5, lower row). This however, should not impact the entrapment of these very large ( 5-30 $\mu \mathrm{m})$ crystals within the permanent extracellular environment of solid tumors. 
Figure 4. Hydrolysis of ${ }^{125} \mathrm{IQ}_{2-\mathrm{P}}$ following 5-min incubation in AP or PAP at various $\mathrm{pH}$ values, indicating that dephosphorylation is favored at lower $\mathrm{pH}$.

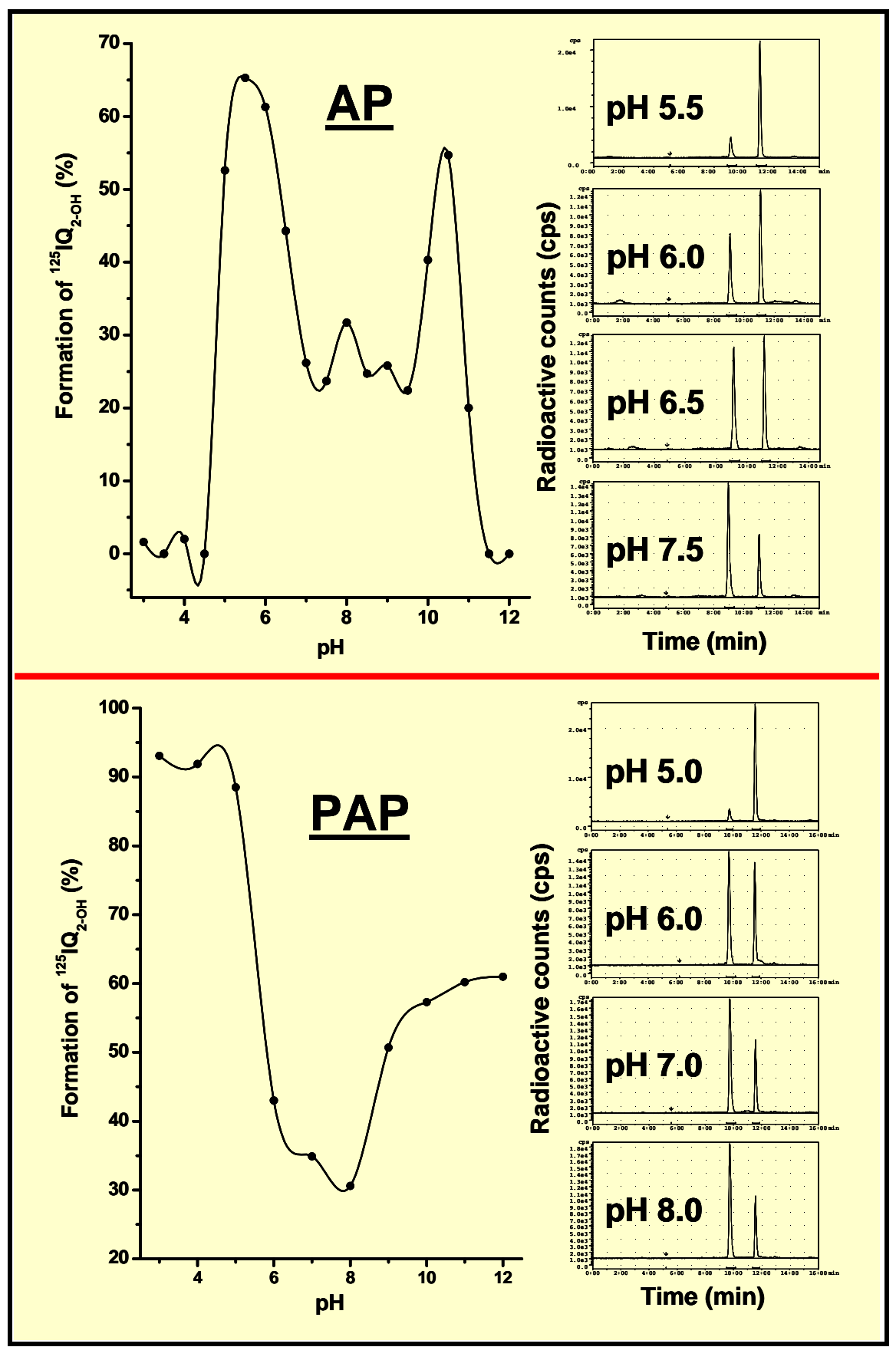

As mentioned above, the extracellular $\mathrm{pH}$ of solid tumors is somewhat acidic ( $\sim 6.5)$. Consequently, it was essential to ascertain that the iodinated $\mathrm{Q}_{2-\mathrm{P}}$ derivatives are hydrolyzed by tumor cells when the extracellular $\mathrm{pH}$ is acidic. Therefore, viable human pancreatic tumor cells (T3M4) were incubated with $\mathrm{IQ}_{2-\mathrm{P}}$ in media whose $\mathrm{pH}$ had been pre-adjusted to 6.5, 7.0, and 7.4. Such experiments indicate that lowering the $\mathrm{pH}$ leads to the earlier appearance of many more fluorescent $\mathrm{IQ}_{2-\mathrm{OH}}$ crystals (Figure 6). Taken together with our results showing that AP- and PAP-mediated dephosphorylation occurs most efficiently at acidic $\mathrm{pH}$ (Figure 4), we expect that iodinated $\mathrm{Q}_{2-\mathrm{P}}$ analogs - upon administration to 
tumor-bearing animals - will be more readily and efficiently hydrolyzed within the extracellular tumor than in the normal tissue environment.

Figure 5. Fluorescence microscopy of viable human TE671 rhabdomyosarcoma cells incubated $\left(37^{\circ} \mathrm{C}\right)$ in vitro $(\mathrm{pH} 7.4)$ with $\mathrm{IQ}_{2-\mathrm{P}}$ analogs, showing hydrolysis and crystallization of these derivatives (green). Note different size and intensity of crystals formed. (A, C, and E) low power - cells not washed. (B, D, and F) high power -cells washed with PBS, fixed in methanol, and nuclei counterstained with DAPI (blue).

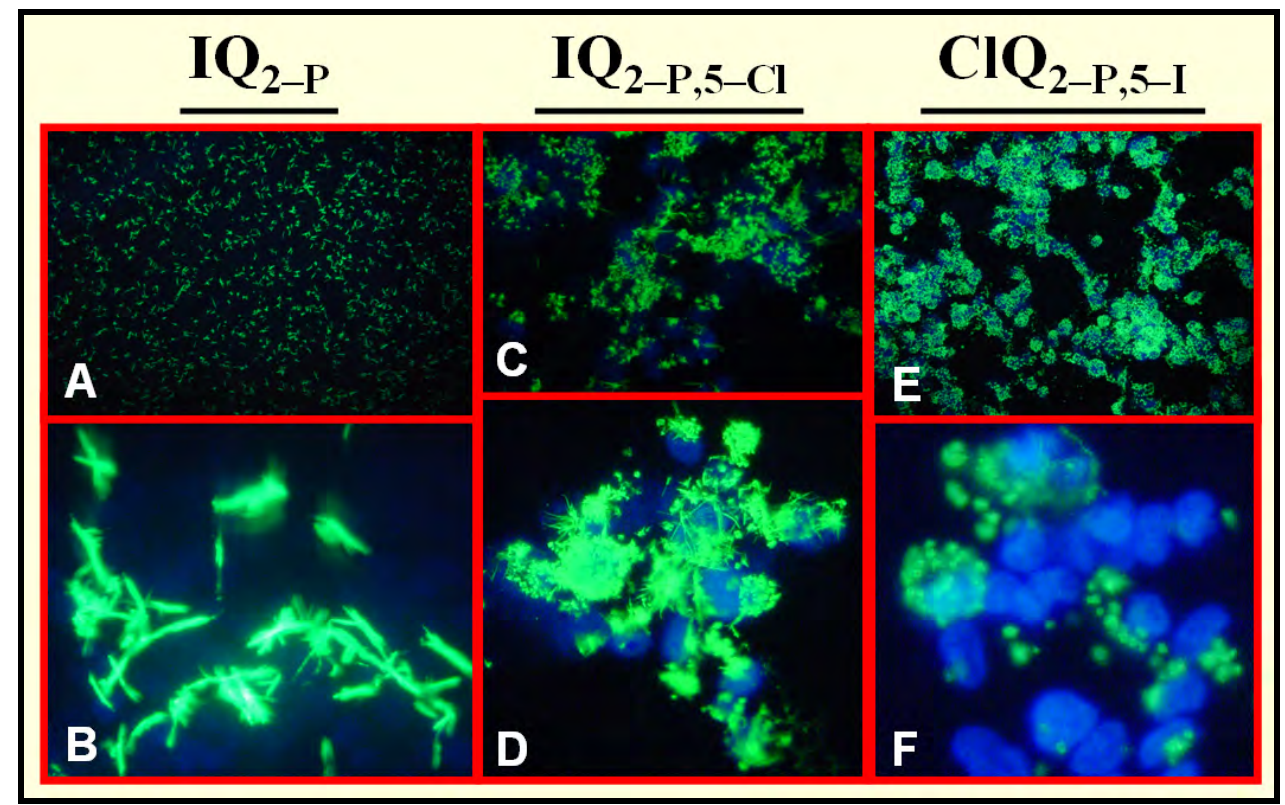

Specific Localization of $I_{2-P}$ in AP-Rich Regions and Entrapment of $\mathrm{IQ}_{2-\mathrm{OH}}$ within Tissues

For EMCIT to succeed, it is essential to demonstrate the site-specific hydrolysis of the watersoluble iodinated phosphoquinazolinone derivatives to their water-insoluble analogs in AP-rich regions within an animal. In one study, we injected mice subcutaneously (s.c.) with either AP or inactivated AP and then administered i.v. ${ }^{125} \mathrm{IQ}_{2-\mathrm{P}}$. When the radioactivity in the injected forelimb was measured, it became clear that it was proportional to the amount of AP present ( $4 \%$ injected dose per gram forelimb). That these increases are due to the enzymatic action of AP is ascertained by the absence of radioactive uptake in the forelimb of mice pre-injected with inactivated AP [2]. The findings illustrate the specific dose-dependent accumulation of $\mathrm{IQ}_{2-\mathrm{P}}$ (more accurately $\mathrm{IQ}_{2-\mathrm{OH}}$ ) within AP-containing sites in an animal.

Another foundation upon which the success of the EMCIT technology depends is the permanent retention of radioactivity within the tissue following radioiodinated prodrug hydrolysis. To assess this in vivo, ${ }^{125} \mathrm{IQ}_{2-\mathrm{OH}}$ was injected s.c. into the forelimb of mice (for comparison, ${ }^{125} \mathrm{IQ}_{2-\mathrm{P}}$ was injected s.c. into the contralateral forelimb). The animals were killed and the percentage injected dose of radioactivity associated with the forelimbs determined. Whereas $>99 \%{ }^{125} \mathrm{IQ}_{2-\mathrm{P}}$ seeps from the s.c. pocket by $24 \mathrm{~h}, 71 \pm 5 \%{ }^{125} \mathrm{IQ}_{2-\mathrm{OH}}$ activity remains at the injection site [2]. More notable for the premise 
of the EMCIT approach, there is no change in the radioactivity in the forelimb of the animals at $48 \mathrm{~h}$, indicating that $\mathrm{IQ}_{2-\mathrm{OH}}$ is permanently and indefinitely trapped within tissues. Similar findings are obtained when ${ }^{125} \mathrm{IQ}_{2-\mathrm{P}}$ and ${ }^{125} \mathrm{IQ}_{2-\mathrm{OH}}$ are injected into the livers of mice (i.e., rapid elimination of radioactivity post ${ }^{125} \mathrm{IQ}_{2-\mathrm{P}}$ injection and retention of radioactivity after ${ }^{125} \mathrm{IQ}_{2-\mathrm{OH}}$ injection).

Figure 6. Fluorescence microscopy of viable human T3M4 pancreatic tumor cells incubated $\left(37^{\circ} \mathrm{C}\right)$ in vitro with $\mathrm{IQ}_{2-\mathrm{P}}$ in media at varying $\mathrm{pH}$, showing that prodrug is hydrolyzed more efficiently and more rapidly at pH 6.5. Columns 1-3: low power - cells not washed; column 4: high power - cells washed with PBS, fixed in methanol, and nuclei counterstained with DAPI.

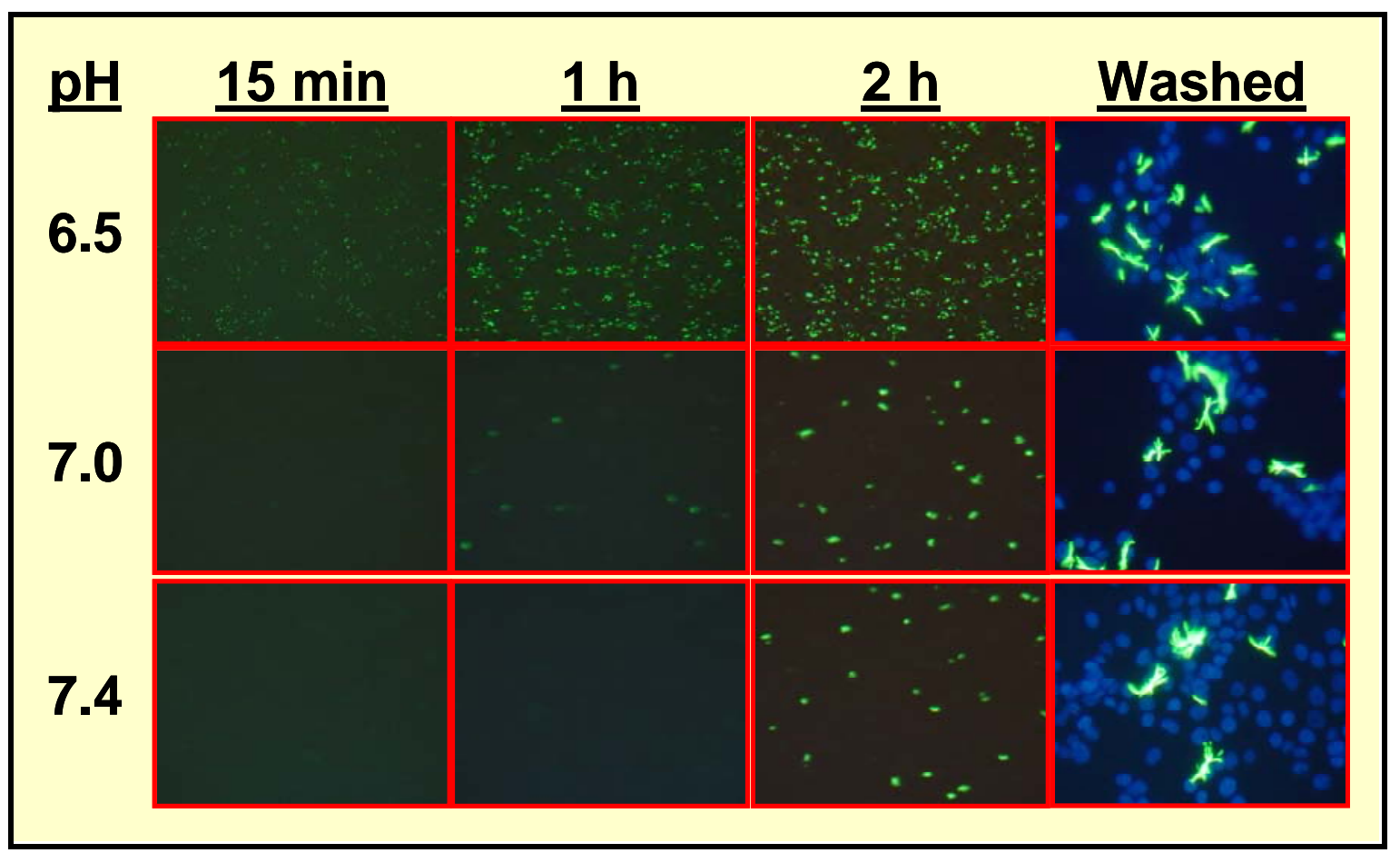

In Vivo Localization of ${ }^{125}$ I-Labeled $Q_{2-P}$ in Tumor-Bearing Mice and High Tumor-to-Normal Tissue (T/NT) Ratios

In one of our studies [3], nude rats bearing palpable s.c. human TE671 rhabdomyosarcoma tumors (a human tumor-cell line that rapidly and efficiently hydrolyzes $\mathrm{IQ}_{2-\mathrm{P}}$ to $\mathrm{IQ}_{2-\mathrm{OH}}$ in vitro) were injected intratumorally or intramuscularly (thigh) with HPLC-purified ${ }^{125} \mathrm{IQ}_{2-\mathrm{P}}(>99 \%$ purity) and were killed one day later. The radioactivity within the tumors, blood, injected muscle, and contralateral muscle was then determined. The findings demonstrate that $\sim 70 \%$ of the injected dose is retained within the injected tumors and only $1 \%$ is found within the injected muscle (i.e., 70-fold difference). These results, which also show that the radioactive content of the blood and contralateral muscle is very low, indicate that very high tumor-to-blood $(\sim 700)$ and tumor-to-muscle $(\sim 7,000)$ ratios can be achieved upon the in vivo hydrolysis of these quinazolinone derivatives. In mice bearing intraperitoneal (i.p.) human OVCAR-3 ovarian tumors, the i.p. injection of ${ }^{125} \mathrm{IQ}_{2-\mathrm{P}}$ leads to moderate T/NT ratios (Figure 7). 
Figure 7. T/NT ratios in mice bearing i.p. OVCAR-3 tumors and injected i.p. $24 \mathrm{~h}$ earlier with ${ }^{125} \mathrm{IQ}_{2-\mathrm{P}}$.

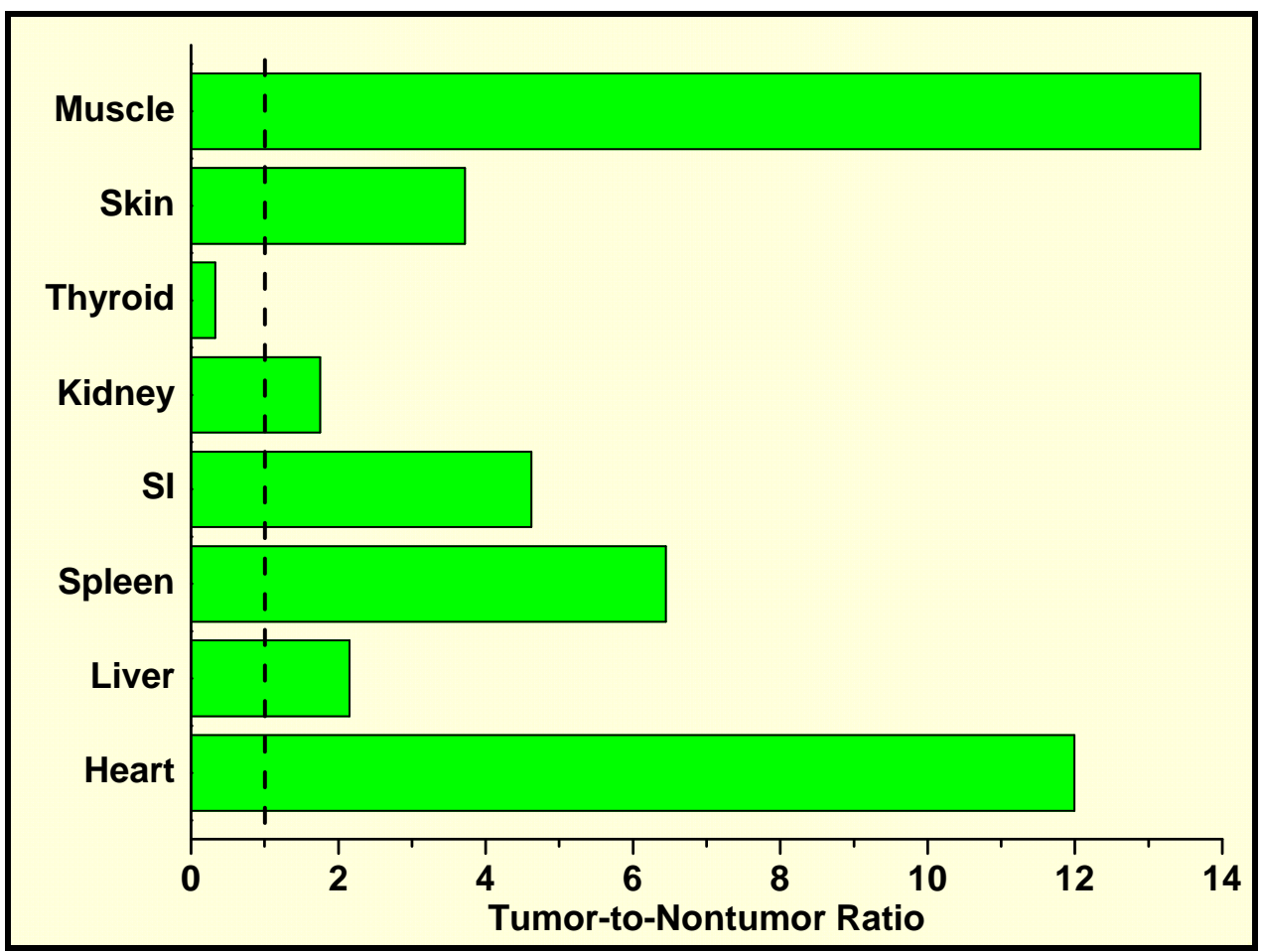

\section{Conclusions}

We have been developing a novel proprietary technology (EMCIT) that aims to concentrate radioimaging and radiotherapeutic compounds within solid tumors. The approach is a method for extracellular enzyme-dependent, tumor-specific, in vivo hydrolysis of water-soluble compounds to water-insoluble precipitating entities that are entrapped within solid tumors. Toward these ends, we have: (i) used data mining to identify enzymes overexpressed extracellularly by various human tumors; (ii) employed in silico methods to characterize the active site and binding pocket of the identified enzyme(s); and (iii) defined possible pharmacophores, examined in silico their interactive mode with the enzyme(s), and performed three-dimensional quantitative structure-activity relationship analysis. These studies have led to the determination that the hydrolytic enzymes (e.g., AP, PAP) are overexpressed extracellularly by various human tumor-cell types, and to the identification and synthesis of several iodinated (e.g., ${ }^{123} \mathrm{I} /{ }^{125} \mathrm{I} /{ }^{127} \mathrm{I} /{ }^{131} \mathrm{I}$ ) phosphoryloxyquinazolinone derivatives. The $\mathrm{IQ}_{\mathrm{P}}$ derivatives are: (i) negatively charged, 3-ring, highly water-soluble structures (repelled by negatively charged mammalian plasma membranes); (ii) excellent substrates for AP and PAP; and (iii) upon incubation with such phosphatases, rapidly and efficiently dephosphorylated to neutral, 4-ring, highly water-insoluble, fluorescent $\mathrm{IQ}_{2-\mathrm{OH}}$ analogs. Furthermore: (i) the in vitro incubation of $\mathrm{IQ}_{2-\mathrm{P}}$ derivatives with various viable human tumor cells, but not normal cells, causes their dephosphorylation, more than a millionfold decrease in their water solubility, and the extracellular formation of large water-insoluble $\mathrm{IQ}_{2-\mathrm{OH}}$ fluorescent crystals; (ii) i.v. injection of ${ }^{125} \mathrm{IQ}_{2-\mathrm{P}}$ into normal mice does not lead to the accumulation or retention of radioactivity by normal tissues; (iii) ${ }^{125} \mathrm{IQ}_{2-\mathrm{OH}}$ is indefinitely retained at the site where it is formed in vivo; (iv) i.v. administration of ${ }^{125} \mathrm{IQ}_{2-\mathrm{P}}$ in mice 
results in the accumulation of radioactivity specifically in subcutaneous pockets preinjected with AP; (v) intratumoral injection of $\mathrm{IQ}_{2-\mathrm{P}}$ leads to excellent entrapment of $\mathrm{IQ}_{2-\mathrm{OH}}(\sim 70 \% \mathrm{ID} / \mathrm{g})$ within solid tumors and very high T/NT ratios; (vi) intraperitoneal injection of $\mathrm{IQ}_{2-\mathrm{P}}$ into mice bearing i.p ovarian tumors leads to favorable T/NT ratios; (vii) the prodrug being radioactive, therapeutic effectiveness does not depend on internalization of radiopharmaceutical by tumor cells or on targeting every tumor cell (cross-fire irradiation).

\section{Acknowledgments}

This work was supported in part by Department of Defense grants (PI: A.I. Kassis) W81XWH-061-0204 (Radiodiagnosis and Radiotherapy of Ovarian Cancer), W81XWH-04-1-0499 (Radiodetection and Radiotherapy of Breast Cancer), and W81XWH-06-1-0043 (Radioimaging and Radiotherapy of Prostate Cancer).

\section{References}

1. Kassis, A.I.; Harapanhalli, R.S. Methods for enzyme-mediated tumor diagnosis and therapy. U.S. Patent Pending, 2001; application no. 2001-839779.

2. Ho, N.; Harapanhalli, R.S.; Dahman, B.A.; Chen, K.; Wang, K.; Adelstein, S.J.; Kassis, A.I. Synthesis and biologic evaluation of a radioiodinated quinazolinone derivative for enzymemediated insolubilization therapy. Bioconj. Chem. 2002, 13, 357-364.

3. Chen, K.; Wang, K.; Kirichian, A.M.; Al Aowad, A.F.; Iyer, L.K.; Adelstein, S.J.; Kassis, A.I. In silico design, synthesis, and biological evaluation of radioiodinated quinazolinone derivatives for alkaline phosphatase-mediated cancer diagnosis and therapy. Mol. Cancer Ther. 2006, 5, 30013013.

4. Pospisil, P.; Iyer, L.K.; Adelstein, S.J.; Kassis, A.I. A combined approach to data mining of textual and structured data to identify cancer-related targets. BMC Bioinformatics 2006, 7, 354.

5. Chen, K.; Al Aowad, A.F.; Adelstein, S.J.; Kassis, A.I. Molecular-docking-guided design, synthesis, and biologic evaluation of radioiodinated quinazolinone prodrugs. J. Med. Chem. 2007, 50, 663-673.

6. Pospisil, P.; Wang, K.; Al Aowad, A.F.; Iyer, L.K.; Adelstein, S.J.; Kassis, A.I. Computational modeling and experimental evaluation of a novel prodrug for targeting the extracellular space of prostate tumors. Cancer Res. 2007, 67, 2197-2205.

7. Wang, K.; Kirichian, A.M.; Al Aowad, A.F.; Adelstein, S.J.; Kassis, A.I. Evaluation of chemical, physical, and biologic properties of tumor-targeting radioiodinated quinazolinone derivative. Bioconjugate Chem. 2007, 18, 754-764.

8. Kassis, A.I. Compounds and methods for enzyme-mediated tumor imaging and therapy. U.S. provisional patent pending, 2007.

9. Kassis, A.I. Radiotargeting agents for cancer therapy. Expert Opin. Drug Deliv. 2005, 2, 981-991.

10. Blaschke, C.; Yeh, A.; Camon, E.; Colosimo, M.; Apweiler, R.; Hirschman, L.; Valencia, A. Do you do text? Bioinformatics 2005, 21, 4199-4200.

11. NCBI PubMed, http://www.ncbi.nlm.nih.gov/entrez/query.fcgi. 
12. UniProt, the Universal Protein Resource, http://www.pir.uniprot.org/.

13. NCBI Entrez Gene (supercedes LocusLink), http://www.ncbi.nlm.nih.gov/projects/LocusLink/.

14. IT.Omics LSGraph ${ }^{\circledR}$, http://lsgraph.it-omics.com/.

15. Ingenuity ${ }^{\circledR}$ Systems, http://www.ingenuity.com/products/pathways_analysis.html.

16. Davies, J.O.; Davies, E.R.; Howe, K.; Jackson, P.C.; Pitcher, E.M.; Sadowski, C.S.; Stirrat, G.M.; Sunderland, C.A. Radionuclide imaging of ovarian tumours with ${ }^{123}$ I-labelled monoclonal antibody (NDOG2) directed against placental alkaline phosphatase. Br. J. Obstet. Gynaecol. 1985, 92, 277-286.

17. Critchley, M.; Brownless, S.; Patten, M.; McLaughlin, P.J.; Tromans, P.M.; McDicken, I.W.; Johnson, P.M. Radionuclide imaging of epithelial ovarian tumours with ${ }^{123}$ I-labelled monoclonal antibody (H317) specific for placental-type alkaline phosphatase. Clin. Radiol. 1986, 37, 107-112.

18. Stigbrand, T.; Hietala, S.-O.; Johansson, B.; Makiya, R.; Riklund, K.; Ekelund, L. Tumour radioimmunolocalization in nude mice by use of antiplacental alkaline phosphatase monoclonal antibodies. Tumor Biol. 1989, 10, 243-251.

19. Kosmas, C.; Kalofonos, H.P.; Hird, V.; Epenetos, A.A. Monoclonal antibody targeting of ovarian carcinoma. Oncology 1998, 55, 435-446.

20. Le Du, M.H.; Stigbrand, T.; Taussig, M.J.; Ménez, A.; Stura, E.A. Crystal structure of alkaline phosphatase from human placenta at $1.8 \AA$ resolution: implication for a substrate specificity. $J$. Biol. Chem. 2001, 276, 9158-9165.

21. Ho, D.H.W. Distribution of kinase and deaminase of 1- $\beta$-D-arabinofuranosylcytosine in tissues of man and mouse. Cancer Res. 1973, 33, 2816-2820.

22. Ortlund, E.; LaCount, M.W.; Lebioda, L. Crystal structures of human prostatic acid phosphatase in complex with a phosphate ion and $\alpha$-benzylaminobenzylphosphonic acid update the mechanistic picture and offer new insights into inhibitor design. Biochemistry (Mosc) 2003, 42, 383-389.

23. Schneider, G.; Lindqvist, Y.; Vihko, P. Three-dimensional structure of rat acid phosphatase. EMBO J. 1993, 12, 2609-2615.

24. Porvari, K.S.; Herrala, A.M.; Kurkela, R.M.; Taavitsainen, P.A.; Lindqvist, Y.; Schneider, G.; Vihko, P.T. Site-directed mutagenesis of prostatic acid phosphatase: catalytically important aspartic acid 258, substrate specificity, and oligomerization. J. Biol. Chem. 1994, 269, 2264222646.

25. Lindqvist, Y.; Schneider, G.; Vihko, P. Crystal structures of rat acid phosphatase complexed with the transition-state analogs vanadate and molybdate: implications for the reaction mechanism. Eur. J. Biochem. 1994, 221, 139-142.

26. Hwang, Y.C.; Kim, S.-G.; Evelhoch, J.L.; Ackerman, J.J.H. Nonglycolytic acidification of murine radiation-induced fibrosarcoma 1 tumor via 3-O-methyl-D-glucose monitored by ${ }^{1} \mathrm{H},{ }^{2} \mathrm{H},{ }^{13} \mathrm{C}$, and ${ }^{31} \mathrm{P}$ nuclear magnetic resonance spectroscopy. Cancer Res. 1992, 52, 1259-1266.

27. Raghunand, N.; Altbach, M.I.; van Sluis, R.; Baggett, B.; Taylor, C.W.; Bhujwalla, Z.M.; Gillies, R.J. Plasmalemmal pH-gradients in drug-sensitive and drug-resistant MCF-7 human breast carcinoma xenografts measured by ${ }^{31} \mathrm{P}$ magnetic resonance spectroscopy. Biochem. Pharmacol. 1999, 57, 309-312. 
28. Gillies, R.J.; Liu, Z.; Bhujwalla, Z. ${ }^{31} \mathrm{P}-\mathrm{MRS}$ measurements of extracellular pH of tumors using 3aminopropylphosphonate. Am. J. Physiol. 1994, 267, C195-C203.

29. Timperley, W.R. Alkaline-phosphatase-secreting tumour of lung. Lancet 1968, 2, 356.

30. Suzuki, H.; Iino, S.; Endo, Y.; Torii, M.; Miki, K.; Oda, T. Tumor-specific alkaline phosphatase in hepatoma. Ann. N. Y. Acad. Sci. 1975, 259, 307-320.

31. Higashino, K.; Kudo, S.; Ohtani, R.; Yamamura, Y. Further observation on Kasahara isoenzyme in patients with malignant diseases. Gann 1976, 67, 909-911.

32. Benham, F.J.; Povey, M.S.; Harris, H. Placental-like alkaline phosphatase in malignant and benign ovarian tumors. Clin. Chim. Acta 1978, 86, 201-215.

33. Nadji, M.; Tabei, Z.; Castro, A.; Morales, A.R. Immunohistological demonstration of prostatic origin of malignant neoplasms. Lancet 1979, 1, 671-672.

34. Loor, R.; Wang, M.C.; Valenzuela, L.; Chu, T.M. Expression of prostatic acid phosphatase in human prostate cancer. Cancer Lett. 1981, 14, 63-69.

35. Wick, M.R.; Swanson, P.E.; Manivel, J.C. Placental-like alkaline phosphatase reactivity in human tumors: an immunohistochemical study of 520 cases. Hum. Pathol. 1987, 18, 946-954.

36. Azumi, N.; Traweek, S.T.; Battifora, H. Prostatic acid phosphatase in carcinoid tumors: immunohistochemical and immunoblot studies. Am. J. Surg. Pathol. 1991, 15, 785-790.

37. Dabare, A.A.N.P.M.; Nouri, A.M.E.; Cannell, H.; Moss, T.; Nigam, A.K.; Oliver, R.T.D. Profile of placental alkaline phosphatase expression in human malignancies: effect of tumour cell activation on alkaline phosphatase expression. Urol. Int. 1999, 63, 168-174.

Samples Availability: Not available.

(C) 2008 by MDPI (http://www.mdpi.org). Reproduction is permitted for noncommercial purposes. 